\title{
La constitucionalización de los derechos del consumidor en Colombia: un análisis desde los derechos sociales fundamentales*
}

\author{
The Constitutionalization of Consumer Rights in Colombia: \\ An Analysis from Fundamental Social Rights \\ Recibido: 20 de marzo de 2013 - Revisado: 30 de mayo de 2013 - Aceptado: 18 de octubre de 2013
}

Beliña Herrera Tapias**

\begin{abstract}
Resumen
Este artículo se constituye de un análisis para una adecuada categorización constitucional del derecho del consumo en Colombia y de la identificación de cada uno de los elementos, actos y relaciones que en verdad integran las relaciones de consumo; las cuales a su vez demandan por su naturaleza misma, una titularidad individual, que asegure un estándar de consumo digno, en la que la dignidad de cada sujeto exige respeto a la libertad personal y económica, satisfacer al orden social en el sentido de permitirle el dominio de un espacio vital mínimo y un estatus socioeconómico que facilite a los individuos una convivencia armoniosa y equilibrada en lo que se refiere a la producción, comercialización, distribución y adquisición de bienes y servicios.
\end{abstract}

\section{Palabras clave}

Economía, titularidad, consumidor, derechos sociales fundamentales, derechos subjetivos, derechos colectivos.

\begin{abstract}
This article provides an analysis for a proper constitutional categorization of consumer rights in Colombia and the identification of each of the elements, acts and relationships that truly integrate the consumer relations, which in turn demand, by their own nature, an individual ownership, to ensure a decent standard of consumption, in which the dignity of each person requires respect for personal and economic freedom, satisfying the social order in the sense of allowing the domain of a minimum living space and socioeconomic status to the individuals so facilitating a harmonious and balanced coexistence in terms of production, marketing, distribution and procurement of goods and services.
\end{abstract}

\section{Key Words}

Economy, ownership, consumer, fundamental social rights, subjective rights, collective rights.

\footnotetext{
* Este artículo es producto de los resultados de la investigación denominada: "Mecanismos judiciales y extrajudiciales de protección al consumidor a partir de la Constitución de 1991", que se desarrolló en el marco de la línea de investigación de asuntos mercantiles del Grupo de Investigaciones en Derecho, Política y Sociedad, financiado por la Facultad de Derecho de la Corporación Universitaria de la Costa.

** Abogada, magíster en Derecho de la Universidad del Norte. Investigadora y líder del Grupo de Investigaciones en Derecho, Política y Sociedad (categoría B Colciencias), de la Facultad de Derecho de la Corporación Universitaria de la Costa, Barranquilla, Colombia.

Correo electrónico:

bherrera3@cuc.edu.co.

Para citar este artículo use: Herrera B. (2013). La constitucionalización de los derechos del consumidor en Colombia: un análisis desde los derechos sociales fundamentales. Revista Civilizar Ciencias Sociales y Humanas, 13(25), 33-48.
} 


\section{Introducción}

Las relaciones económicas y sociales a partir de la modernidad, la fabricación en serie y la Revolución Industrial, permitieron el surgimiento intrínseco de un grupo social especial: los consumidores y usuarios de bienes y servicios, que sin duda generaron un nexo estructural entre varias disciplinas: la ética, la economía, la sociología y el derecho, para la búsqueda de la garantía de sus intereses. Pues bien, en términos de Ghersi (1995) el derecho de consumo es parcialmente un derecho humano fundamental, de tal forma que cada Estado debe respetar y hacer respetar a los sectores económicos este esencial principio de acceso a un consumo digno. La filosofía de este nuevo derecho abarca entonces tres dimensiones humanistas: de promoción, del bienestar general y la calidad de vida, y de contención frente al poder y al sistema económico.

El surgimiento del novedoso derecho del consumo es una respuesta a la necesidad de proteger la natural vulnerabilidad de una de las partes intervinientes en el mercado, que bien podría colocar en riesgo a la misma economía de mercado; y al hacerse del consumidor un sujeto seguro en sus relaciones de consumo, se establecerán vínculos de intercambio confiables y estables que corrijan las fallas económicas.

La tendencia que prevalece en nuestros días gira en torno a que las leyes de defensa de la competencia no están para proteger al mercado sino al destinatario último de la actividad económica. Según Farina (2004), el consumidor -como también sostenía Gide (1926)- es el único que tiene carácter universal, no los demás agentes que intervienen en el proceso económico: se produce para consumir y el sentido último de la actividad económica consiste en satisfacer necesidades humanas (Kemelmajer, 1991).

En Colombia la inclusión legal y constitucional de este derecho del consumo en nuestro ordenamiento jurídico, se debe a una respuesta de necesidad de adecuación de nuestra normativa a los lineamientos internacionales de las directivas de la Organización de las Naciones Unidas (ONU), y de los proyectos del Mercado Común del Sur (Mercosur), ya que las relaciones comerciales, negociaciones internacionales y procesos de globalización e integración de los mercados, requerían de la garantía de este tipo de derechos por los Estados contratantes, sin embargo, la interpretación de las categorías que integran el derecho del consumo, no se ha abordado en su integridad y mucho menos a la luz de los principios constitucionales actuales. Pues bien, a nuestro parecer, una categorización constitucional de los derechos de los consumidores como derechos colectivos y con los mecanismos de acción judicial dados, no es operante ni responde a las necesidades ni realidades del consumidor contemporáneo que vive en un mundo globalizado.

Con las premisas que se expondrán aquí, se establecerá con claridad que los consumidores tienen un rol socialmente definido, no haciéndose necesario que el sujeto esté permanentemente consumiendo, siendo suficiente que ocupe el papel de consumidor en una acción, que puede englobar hechos y actos jurídicos, y contratos (Lorenzetti, 2008).

Entendiendo además que el grupo social de los consumidores y usuarios es heterogéneo por no constituirse simplemente por individuos no profesionales o profesionales, contratantes, $\mathrm{o}$ miembros de un grupo familiar, sino que, como bien expresan las resoluciones del 14 de abril de 1975 y del 19 de mayo de 1981 del Consejo de la Comunidad Europea:

En adelante ya no se considerará al consumidor únicamente como comprador y usuario de bienes y servicios para uso personal, familiar o colectivo, sino como una persona interesada en los diferentes aspectos de la vida social que puede afectarle, directa o indirectamente, en calidad de consumidor y por tanto la política de los consumidores se ha presentado bajo un aspecto defensivo, que debe orientarse de for- 
ma abierta al diálogo creando las condiciones para que el consumidor participe en las grandes decisiones económicas que condicionan su vida en términos de calidad (Resolución del Consejo de la Comunidad Europea del 14 de abril de 1975).

Hablar de consumidores y usuarios significa reflexionar sobre calidad de vida, pues esta trata de requerimientos que de forma habitual el ser humano necesita suplir en condiciones óptimas, por ejemplo: la alimentación, vivienda, trabajo, salud, servicios públicos, educación, entre otros. Así nos ubicamos en una posición jurídica que naturalmente exige del Estado, una acción positiva que tienda, por un lado, a proteger a los consumidores -individualmente considerados de los perjuicios que las relaciones de consumo mismas podrían acarrearles- $\mathrm{y}$, por otro, a preservar el mercado, en cuanto mecanismo de coordinación del proceso económico teniendo en cuenta el interés social que persigue la Carta de 1991 al estructurar un modelo de economía mixto, procurando el bienestar general a partir de los instrumentos constitucionales de libertad e intervención económica y social del Estado en la búsqueda de la igualdad y el equilibrio social.

\section{Planteamiento del problema}

La sociedad de consumo, desde el comienzo se entendió como un modo activo de relacionarse no solo con los objetos, sino también con la comunidad y con el mundo (Baudrillard, 1970). Un modo de actividad sistemática y de respuesta global en el cual se funda todo nuestro sistema cultural. El antropólogo argentino Néstor García Canclini en su obra Consumidores y ciudadanos: conflictos multiculturales de la globalización, afirma que el consumo implica "el conjunto de procesos socioculturales en los que se realizan la apropiación y los usos de los productos" (García, 1995, p. 17). Quiere decir esto, que el consumo comprende un proceso cíclico en el que el hombre produce para consumir y el consumo a su vez genera producción, y es a la vez, el acto por el cual cualquier sujeto económico adquiere bienes y servicios para la satisfacción de sus necesidades.

Esta nueva sociedad concibió el reconocimiento de una inédita categorización de los ciudadanos en consumidores, tal como lo promulgó el presidente estadounidense John F. Kennedy al Congreso de su país el 15 de marzo de 1962. Allí demandó, para esta nueva clase de ciudadanos, un trato equitativo y digno en sus relaciones de consumo, y pidió que se generasen nuevas tareas a los quehaceres propios de la política, la economía y el derecho de forjar al interior de los sistemas, una estructura global que reconociera, garantizara y protegiera "una posición de equilibrio de estos sujetos dentro del mercado en sus relaciones con los proveedores de bienes y servicios en forma masiva" (Stiglitz, 1993, p. 23).

Por otra parte, la igualdad negocial de las partes de la teoría clásica liberal del derecho, consagrada en nuestro ordenamiento por el Código Civil, "se constituye en una ficción dentro de las relaciones de consumo" (Rinessi, 2006, p. IX), ya que el productor, llevado por un proceso de industrialización masivo y de una economía de consumo creciente, olvida la responsabilidad que sobre él recae, de producir con calidad y cumplir con diligencia su actividad. Pues bien, las implicaciones que ocasiona un producto defectuoso vinculan a toda una nueva categoría de ciudadanos que se ve vulnerado en sus derechos.

Es así como surge, en la época moderna, la preocupación por una protección integral al consumidor, como sujeto potencial de nuevas acciones de política legislativa en casi todos los países del mundo,lo que ha hecho que se consagren los derechos de los consumidores a través de preceptos, valores y principios constitucionales, generando un análisis científico dirigido en particular a la conceptualización y ubicación del derecho de consumo en el ordenamiento jurídico, la distinción entre este y su papel en la economía de mercados. 
Colombia no fue ajena al proceso que vivieron las constituciones modernas de salvaguardar los intereses de los consumidores y usuarios de bienes y servicios, puesto que la Constitución Nacional de 1991 los sancionó expresamente, dándole a este tipo de derechos el rango de constitucionales, a través de los artículos 78 y 334, en los que se prescribe la intervención del Estado por mandato de la ley, en la producción, distribución, utilización de los bienes, y en los servicios públicos y privados. Sin embargo, los mecanismos de protección dispuestos en la Carta Magna, no responden a los principios y finalidad buscada por el constituyente colombiano de 1991, al elevar a rango constitucional los derechos en cuestión. Lo que ha suscitado a su vez, una gran inseguridad y discusión jurídica al tratar de proteger estos derechos, teniendo en cuenta el estatus que hoy en día poseen, a través de procedimientos administrativos y procedimientos ordinarios, por responsabilidad civil, acciones de garantía y acciones contractuales que no responden a cabalidad a la garantía que se pretendió darles a los consumidores y usuarios.

Precisamente en este estudio, que incorpora una metodología jurídica de carácter aplicado y el desarrollo de un enfoque cualitativo a la luz de la llamada teoría fundamentada de Strauss y Corbin -que consiste en la construcción de una tesis a través de la recopilación, análisis e investigación de los datos puntuales acerca de quiénes son consumidores, cuál es el real soporte de sus derechos, y a qué categoría constitucional corresponde la naturaleza de tales derechos, de acuerdo con los principios de la Carta de 1991-, nos planteamos como interrogante el siguiente: ¿cuál es la adecuada categoría constitucional de los derechos de los consumidores? Se pretendió obtener conclusiones que logren dar respuesta a las exigencias del consumidor del nuevo siglo y a la problemática propuesta de una debida categorización constitucional, que establezca un contenido coherente con la realidad política, social y económica de los derechos de los consumidores en Colombia.

\section{Los derechos sociales fundamentales frente a los consumidores y usuarios}

Los derechos de los consumidores, como es natural, se forman en una pluridisciplinariedad de gran amplitud y complejidad que no se reduce en exclusiva a la ciencia del derecho para la comprensión de su situación y la consecución de su protección integral. Así, la expresión "sociedad de consumo", no designa tan solo el aspecto del consumo, actividad humana necesaria y etapa propia del proceso económico, sino que implica además, y en específico, una cultura, un modo de vida, una organización de tiempo humano privado, para el consumo, de lo que otras sociedades y otros intereses producen (Madle, 1987). En este sentido, es evidente que el consumo afecta aspectos personales, económicos y sociales de cada uno de los miembros de la sociedad, de ahí la interrelación existente entre las políticas públicas en general -que planifican y ejecutan la economía- y las políticas de consumo, que impactan a los consumidores; a su vez, todo lo que se realice en procura de su defensa, repercute en los demás sectores de actuación política y económica.

Si bien la protección a los derechos de los consumidores trasciende desde hace unas pocas décadas, el objeto de esta política de protección, encuentra una vasta influencia de la teoría económica -neoinstitucionalista-, que extiende sus preocupaciones a los imperativos de eficacia y de racionalidad del sistema económico de un país, que se evidencian en la salvaguardia directa de sus intereses económicos, fijados en el consumo de bienes y servicios.

En Colombia se sustrae de la Constitución Política, que la estructura del Estado económico se basa en un sistema mixto: por una parte, en una economía dentro de un modelo de mercado que hace un reconocimiento expreso al libre ejercicio de cualquier actividad y oficio, y garantiza la propiedad privada (y su función social), la iniciativa privada dentro de un marco de libre competencia y la libertad económica; y 
por otra, en una economía que procura restringir y limitar el mercado en general, permitiendo la dirección e intervención del Estado, sustentado en la garantía de la distribución de la riqueza, estabilización de la economía, producción, distribución, utilización y consumo de bienes y servicios, fijación de la política de precios, intercambio internacional de bienes y servicios, mecanismos de protección de la industria nacional, e inversión directa en los sectores productivos para la satisfacción de las necesidades individuales y colectivas de los ciudadanos, siendo todos ellos consumidores.

Ahora bien, el Estado mismo, en la ejecución de la economía, no puede obviar las garantías sociales a las que está llamado a cumplir y velar como Estado social de derecho, pues para el logro de sus fines no debe dejar de lado al mercado, que en cuanto parte de la sociedad, se vincula como un elemento material esencial de cumplimiento de sus ideales y objetivos, apoyados en la democracia y la dignidad humana. Siendo ello la razón por la que en este sistema mixto que oscila entre libre iniciativa económica e intervencionismo, en el que se estructura Colombia, coexiste un tercer lineamiento, el cual se ordena en la economía solidaria, que permite una especie de colectivización de los bienes de producción, basada en la autogestión y la unión de varias personas en forma asociativa y solidaria que buscan la satisfacción de las necesidades de la comunidad y la obtención de máximos beneficios sociales (López, 2007).

El medio socioeconómico en el que se encuentra inmersa la sociedad moderna, no permite limitar las soluciones a la problemática de los derechos de los consumidores a la política económica, sino que deberá buscar la corrección de las insuficiencias que afectan al mercado, para restablecer el equilibrio entre los poderes respectivos de los actores participantes, así como el acceso a todos los bienes y servicios con sus respectivas garantías, a través de la tutela constitucional de los derechos de los consumidores, quienes son la parte más vulnerable de la relación y sujeto de protección por el Estado.

Es entonces como se ha previsto que se requiere de instituciones jurídicas que protejan a los consumidores -en el entendido que el mercado no puede garantizar determinadas situaciones, tales como la implementación de políticas de defensa efectiva al consumidor-, dejando esta esta tarea en manos de la categorización de los mismos, como derechos sociales esenciales, formándose un vínculo directo entre el mercado y los derechos sociales (Arango, 2005). La realidad que aúna a los consumidores se ve viciada por el dinamismo propio del mercado, adentrándose estas relaciones más allá del campo de la economía, ingresando en el terreno del discurso ideológico que hace referencia a las distintas concepciones relativas a la posibilidad, conveniencia y límites de la intervención del Estado y del derecho en la conformación y en la regulación de las relaciones socioeconómicas.

Es el ámbito del discurso ideológico, el que permitiría una reivindicación de los derechos de los consumidores, teniendo presente que dentro del modelo económico que opta por la libertad económica y una economía de mercado implica un fin de protección al interés general, distinto a optar por un modelo intervencionista con un gran aparato administrativo que intervenga altamente en las políticas y relaciones económicas, pues lo que en realidad se persigue a través de grandes burocracias, es la consecución de intereses escondidos y específicos (Rincón, 2004).

Lo que nos conduce a la presunta contradicción de los principios de igualdad y libertad, pues algunos pensadores como Milton Friedman, aseguran que reconocer derechos de contenido social y generar una amplia estructura administrativa que intervenga desmedidamente en la economía, produce verdadera desigualdad entre los sujetos del mercado y dentro de estos, los consumidores, ya que un férreo intervencionis- 
mo puede limitar las libertades y generar nuevas cargas al racionalizar los procesos económicos, limitarlos y constituirlos.

Por último, se va a revelar en la función económica desarrollada por las empresas y en las desarrolladas por los consumidores, una contraposición de intereses, en la que la formación de fuertes estructuras de poder, terminarán siempre sometiendo al consumidor. Pues bien, el mismo juego del mercado resuelve a favor de los intereses empresariales, en la medida en que las empresas ostentan una posición de poder dentro del sistema, como situación estructural, y su contenido, si bien en gran parte es económico, no debe limitarse solo a ello (Rebollo, 1990).

En tanto la situación de vulnerabilidad de los consumidores conlleva a una mutación de la concepción inicial de tales derechos y que el Estado intervenga adoptando un modelo ideológico que propugne por las condiciones tanto económicas como sociales, necesarias para la concreción de un desarrollo económico con justicia social; lo cual fue el mensaje dirigido por el presidente Kennedy al Congreso de los Estados Unidos en 1962, momento en el que convencionalmente nace dicha política.

Es así como las constituciones modernas reciben una vasta influencia del constitucionalismo social, que incorporó los derechos sociales como aquellos que daban respuesta a las nuevas funciones y prestaciones exigibles al Estado, en procura del mejoramiento de la calidad de vida y consecución del bienestar general, del que ahora también hacían parte los intereses de un nuevo grupo identificable: los consumidores.

Debemos definir y caracterizar entonces qué son derechos sociales fundamentales, no sin abordar antes el concepto de derechos fundamentales. Para Alexy (1997), estos derechos se definen como "posiciones tan importantes que su otorgamiento no puede quedar en manos de la simple mayoría parlamentaria" (p. 167).
Según Arango (2005), los derechos fundamentales son "derechos subjetivos con un alto grado de importancia" (p. 89). Ahora bien, otros han entendido que los derechos fundamentales, como aquellos que se encuentran positivizados en una constitución, son los derechos humanos, que se consideran esenciales para el ordenamiento jurídico y para el sistema político de un país y, por tanto, poseen un estatus especial con relación a su tutela y reforma.

Al respecto, la Corte Constitucional de Colombia se pronunció en la sentencia T-406, de junio 5 de 1992, en el siguiente sentido:

Esta Corte considera que para que un derecho tenga la calidad de fundamental debe reunir unos requisitos esenciales. De otro lado para la identificación de un derecho de tal naturaleza existen unos criterios que ponen en evidencia los requisitos señalados $\mathrm{y}$, de contera, el derecho fundamental mismo (...). Los derechos fundamentales son, como todas las normas constitucionales, emanación de los valores y principios constitucionales, pero su vinculación con estos es más directa, más inmediata, se aprecia con mayor evidencia. Todo derecho fundamental debe ser emanación directa de un principio.

Según la Corte Constitucional (1992)

Para que un derecho constitucional pueda ser considerado como fundamental, debe además ser el resultado de una aplicación directa del texto constitucional, sin que sea necesario una intermediación normativa; debe haber una delimitación precisa de los deberes positivos [hacer intervención] o negativos [de no intervención] a partir del sólo texto constitucional. Por lo tanto, en normas que poseen una "textura abierta", como por ejemplo las que establecen meros valores constitucionales, a partir de la cual el legislador entra a fijar el sentido del texto, no podrían presentarse la garantía de la tutela. Está claro que no puede ser fundamental un derecho cuya eficacia depende de decisiones políticas eventuales (Sentencia T-406/1992).

De las anteriores concepciones acerca de los derechos fundamentales, hallamos un punto 
de intersección, esto es, el alto grado de importancia que estos deben poseer para considerarse como tal, circunscribiéndose dicha importancia, a dos grandes ámbitos, por un lado, el axiológico, por estar vinculados íntimamente al ser humano y su dignidad y, por otro, al deontológico en cuanto lo que ha de ser, lo obligatorio, lo justo y lo adecuado. Así se forja un nexo primordial entre la justificación filosófica y jurídica de los mismos.

De estos mismos conceptos, se abre un interrogante y es si necesariamente para concebir un derecho como fundamental, se requiere de su consagración constitucional. Se vislumbra que por poseer un alto grado de importancia y por ser preceptos tan íntimamente ligados al hombre y su desarrollo en sociedad, dicha positivización está orientada a reconocerlos y a darles una mayor protección, no siendo posible su modificación por simples leyes. El alto grado de importancia del derecho respectivo se reconoce automáticamente mediante su consagración constitucional.

Otro aspecto en el cual debe pensarse, son los llamados derechos fundamentales no escritos o innominados, que tocan directamente a los derechos humanos, a los que se reconoce su relevancia por medio de normas supranacionales y no en la Carta Magna. No obstante, el grado de importancia de un derecho -derechos humanos- no es condición suficiente para la existencia de un derecho fundamental. Podría entonces pensarse que los derechos fundamentales además deben estar relacionados con la norma jurídica fundamental, con una obligación jurídica fundamental y con una posición fundamental del derecho (Arango, 2005).

Pero concluir que solo el derecho positivizado puede contar como fundamental, sería dejar por fuera el reconocimiento iusfundamental que se estima de un derecho, que bien podría tener razones de peso, que de modo interpretativo podrían considerarse. La distinción entre derechos enumerados y no enumerados, como se usa por lo común en la teoría constitucional, no tiene sentido, porque confunde la referencia con la interpretación. Pues bien, la carta de derechos contiene principios amplios y abstractos de moral política que en nuestra cultura pueden cimentar un derecho constitucional individual; el punto central sobre aplicar principios a controversias políticas no es uno de referencia, sino uno de interpretación, que es muy diferente.

Consideramos entonces que por la estructura misma de los derechos fundamentales, de tan elevada relevancia, estos no pueden limitarse tan solo a aquellos que unos pocos han concebido positivizar, olvidando el dinamismo del derecho, la jurisprudencia y el desarrollo del hombre. El derecho no es solo aquello que está escrito, máxime si cobra una posición jurídica que justifica su reconocimiento por vía interpretativa, y que bien la estimación negativa del mismo traería consigo consecuencias inaceptables para el individuo.

De acuerdo con Arango (2005), los derechos fundamentales, desde la función que estos cumplen en la relación Estado-ciudadano, se clasifican según gran parte de la doctrina jurídica constitucional, en derechos de defensa y derechos de prestación. Los primeros se refieren principalmente a la acción negativa del Estado, colocando límites al Estado, para garantizar los espacios de libertad individual. Los derechos de prestación aluden a los derechos a la acción positiva del Estado (a un hacer estatal), la cual asegura la participación del ciudadano en prestaciones normativas -por ejemplo los derechos de organización o procedimiento- o la participación del ciudadano en prestaciones fácticas -por ejemplo al derecho mínimo vital-. Los primeros se llaman derechos a prestaciones en el sentido amplio, los segundos a prestaciones en sentido más estrecho (Alexy, 1997).

Esta clasificación de los derechos fundamentales nos lleva a las categorías, que del complejo proceso de reconocimiento generacional de los derechos humanos, se han logrado 
consolidar a lo largo de la historia en los actuales Estados modernos; en donde en la primera fase histórica, las declaraciones se limitaron a la proclamación de los derechos civiles y políticos, los que generarían de manera exclusiva obligaciones negativas o de abstención, un no hacer por parte del Estado (Abramovich, \& Courtis, 2002). Mientras que en una segunda etapa se fue abriendo lentamente el camino al reconocimiento de otros derechos que no solo eran nuevos en relación con los antes consagrados, sino que respondían a preocupaciones sociopolíticas diferentes y protegían intereses individuales distintos (De Castro, 1993).

En el criterio de Alexy (1997), estos derechos son, en efecto, los derechos sociales, consagrados constitucionalmente en el primer tercio del siglo XX. Los derechos sociales fundamentales, son incluidos en los derechos fundamentales de prestación en su sentido estricto, definiéndolos como derechos subjetivos que implican la acción positiva del Estado, tal como también lo ha sostenido la Corte Constitucional expresando que:

El Estado ha de abstenerse de realizar acciones orientadas a desconocer estos derechos y con el fin de lograr la plena realización en la práctica de todos estos derechos es preciso, también, que el Estado adopte un conjunto de medidas y despliegue actividades que implican exigencias de orden prestacional (Sentencia T-160/2011).

Lo que refleja a su vez un carácter general de los derechos sociales fundamentales que puede explicarse en tres planos: primero, el plano del titular del derecho: todas las personas son portadoras de derechos sociales fundamentales, pero los obligados son los Estados democráticos modernos. Luego en el plano del objeto, que son derechos constitucionales (es decir, no simples derechos legales) a una situación fáctica que puede alcanzarse mediante la creación de derechos especiales. Y por último, en el ámbito de la fundamentación filosófica, donde los derechos sociales fundamentales son derechos humanos cuyo carácter ideal (validez moral) se ha fortalecido mediante su positivización (validez jurídica) (Arango, 2005).

\section{Estructura y contenido de los derechos so- ciales fundamentales}

Para Arango (2005) puede establecerse la estructura de los derechos sociales fundamentales como derechos subjetivos, a partir de los titulares del derecho como de las obligaciones correlativas, a la vez que se va enmarcando el contenido de los mismos, por lo que consideramos que esta postura denota el logro alcanzado por los individuos y la comunidad ante la organización estatal, lo que les permite la protección de sus intereses más relevantes a través de un reconocimiento jurídico y político.

Respecto al contenido de los derechos sociales fundamentales, en la medida en que estos deben garantizarse en una constitución democrática moderna, Arango (2005) distingue tres tesis: minimalista, maximalista e intermedia, así:

1. Tesis minimalista: los derechos sociales fundamentales deben ser reconocidos en cierto grado. Esto significa que existe un mínimo jurídico constitucional de derechos positivos generales, reconocido o que debe ser reconocido por cualquier Estado constitucional y democrático moderno. En la doctrina jurídica, ese mínimo se denomina "derecho a un mínimo vital".

2. Tesis maximalista: los derechos sociales fundamentales deben garantizarse a cualquiera, en cualquier circunstancia. Estos incluyen los derechos a la alimentación, a la salud, a la vivienda, al trabajo y a la seguridad social, y presuponen normas, obligaciones y posiciones jurídicas cuyo reconocimiento debería ser universal, sin limitarlo a determinadas personas. 
3. Tesis intermedia: solo algunos de los derechos sociales fundamentales son derechos subjetivos. Así, el derecho a la educación es un derecho subjetivo. Que algunos derechos sociales fundamentales - de acuerdo con Peter Badura (1975) - deban concebirse como derechos subjetivos, no significa que esa condición se extienda a todos los derechos sociales fundamentales.

El contenido de los derechos sociales fundamentales más idóneo según estas tres tesis, parece ser la primera teoría, ajustándonos al concepto que se viene desarrollando en este artículo, sin embargo, reconocidos doctrinantes como Gurvitch, Isensee y Requejo Pagés, consideran que este debe ser determinado por el legislador, pues es impensable su eficacia sin una activa intervención de este. Es más, tanto por la legitimidad de los órganos de los que proviene, como por su alcance potencialmente generalizable, la ley es una fuente privilegiada de producción jurídica en los ordenamientos modernos, y constituye una garantía primaria de la satisfacción de cualquier derecho (Pisarello, 2007).

Algunos autores como Alexy (1997), proponen un modelo para establecer dicho contenido, pues según él, este se puede determinar racionalmente. Con base en su teoría de los principios asevera que: una posición de prestación jurídica está en definitiva garantizada iusfundamentalmente, si exige con urgencia el principio de libertad fáctica y el principio de la separación de poderes y el de la democracia. También si reclama principios materiales opuestos (en especial, aquellos que apuntan a la libertad jurídica de otros), que son afectados en una medida relativamente reducida, a través de la garantía iusfundamental de la posición de prestación jurídica y de las decisiones del Tribunal Constitucional que la toman en cuenta. Estas condiciones están satisfechas en el caso de los derechos fundamentales sociales mínimos, por ejemplo, a una vivienda simple, a un mínimo vital, a la educación escolar y a un nivel estándar mínimo de asistencia médica (Alexy, 1997).

A los derechos sociales fundamentales se les atribuye la estructura de una relación jurídica tripartita: el portador del derecho, el obligado y el objeto del derecho. En este sentido, se plantea el siguiente interrogante: ¿los titulares de los derechos sociales fundamentales deben ser individuos, o también pueden serlo grupos?

La pregunta acerca de la titularidad de los derechos sociales fundamentales se liga de forma profunda con la posición jurídica del sujeto de derecho dentro de un orden jurídico, respecto al cual es posible argumentar válidamente, como característica de este tipo de derechos, que se derivan del concepto de derecho subjetivo. Para algunos pensadores como Alexy (1997) y Habermas ( 1999) no hay lugar a duda de que los titulares de los derechos sociales fundamentales son en exclusiva individuos, es decir, son derechos individuales, no son ni metas políticas, ni derechos colectivos. Según Arango (2005), aunque en la teoría los derechos colectivos pueden ser compatibles con el Estado democrático y constitucional de derecho, las colectividades (grupos de individuos) no son consideradas como titulares de derechos sociales fundamentales.

Se entiende por individuos a los seres humanos particulares, a quienes se les considera el sujeto por excelencia de los ordenamientos jurídicos modernos. Desde una perspectiva filosófica, el derecho moderno es individualista, "porque convierte a la persona en sujeto de derechos subjetivos"(Habermas, 1999, p. 250). Ahora, en el marco del modelo de tres niveles de los derechos subjetivos es determinante que el derecho como tal, es decir, la posición jurídica que subyace cuando existe un derecho, sea un derecho del individuo $\mathrm{y}$, por ende, un derecho individual. Este concepto del derecho individual queda abarcado con el término del derecho subjetivo de la dogmática jurídica, en 
tanto todos los derechos individuales son derechos subjetivos, y todos los derechos subjetivos del individuo son derechos individuales. (Alexy,1995, p. 234)

A la tesis de los derechos sociales fundamentales como derechos adscritos al concepto de los derechos subjetivos, se oponen los que dicen que no son derechos individuales; sino disposiciones sobre metas políticas o simples enunciados programáticos (Friauf, 1996).

Desde la perspectiva del derecho del consumo y de la posición jurídica de los derechos, en cuanto enmarcan la diferencia de cada titular del derecho, se hace necesaria la diferenciación entre derechos individuales y metas políticas. Según Dworkin

Un derecho es una meta política individualizada. Un individuo tiene derecho a una oportunidad o recurso o libertad si tal cosa tiende a favorecer una decisión política en virtud de la cual resultará favorecido el estado de cosas que le permite gozar del derecho, aun cuando con esa decisión política no se sirva a ninguna otra meta política, e incluso cuando se la perjudique; y cuando en contra de tal decisión pesa que ella retardaría o pondría en peligro tal estado de cosas, aun cuando ello sea útil a otra meta política (1984, p. 159).

Para aclarar la diferencia entre meta política y derecho, Dworkin manifiesta que:

Decir que la libertad de expresión es un derecho, y no un objetivo, porque los ciudadanos tienen derecho a esa libertad como cuestión de moralidad política, y que el incremento de la fabricación de municiones es un objetivo, no un derecho, porque contribuye al bienestar colectivo, pero ningún fabricante determinado tiene derecho a firmar contrato con el Estado (1984, p. 160).

Por otra parte, define la meta política diciendo que:

Una meta es una finalidad política no individualizada, es decir, un estado de cosas cuya especificación no requiere así una oportunidad, recurso o libertad en particular para individuos determinados. Las metas colectivas apoyan la coordinación de costos y beneficios en la comunidad, con el fin de generar un beneficio global para toda la comunidad. La eficacia económica es una meta colectiva (Dworkin, 1984, p. 160).

\section{O dicho de otra forma:}

Un derecho abstracto es una meta política general cuyo enunciado no indica cómo se ha de comparar el peso de esa meta general con el de otras metas políticas, en determinadas circunstancias, o a qué compromiso se ha de llegar entre ellas. Los derechos concretos, por su parte, son metas políticas definidas con mayor precisión, de manera que expresan más claramente el peso que tienen contra otras metas políticas en determinadas ocasiones (Dworkin, 1984, p. 162).

Una vez aclarada la distinción entre derechos y metas políticas, retomamos la cuestión sobre la titularidad de los derechos sociales fundamentales. Podemos decir que esta depende de la argumentación que justifique su adscripción a normas de derechos fundamentales, la cual se logra mediante argumentos apropiados y adecuados que reconozcan la posición del sujeto de derecho y que cualquiera que se encuentre en esa situación pueda recibir el mismo trato. Pues bien, un argumento apropiado es aquel que ofrece razones válidas y suficientes, un argumento en el que tan solo es posible una respuesta correcta, mostrándose que la titularidad del derecho es el resultado del reconocimiento de una posición jurídica del individuo.

La segunda parte del interrogante trata sobre si las colectividades pueden ser titulares de los derechos sociales fundamentales. Los derechos colectivos pueden definirse de acuerdo con Buchanan (1994), quien sostiene que para que un derecho sea un derecho de grupo, es necesario que pueda ejercerse en una de las siguientes alternativas. Primero, el derecho solo puede ejecutarse en forma no individual. En 
este caso, los individuos, como tales, no tienen la titularidad del derecho. Ejemplos de derechos de grupos no individuales son los diversos derechos de autogobierno interno poseído por las tribus indígenas americanas. Segundo, algunos derechos grupales tienen lo que puede llamarse una posición dual: cualquier individuo que es miembro del grupo puede practicarlos, o el derecho debe ser ejercido no individualmente sino mediante un mecanismo colectivo por algún agente o agentes en nombre del grupo. Un caso de un derecho grupal de posición dual, es el derecho a participar en ceremonias o rituales culturales o religiosos (Buchanan, 1994). Esta sería una definición amplia acerca de este tipo de derechos y que se basa en la praxis colectiva de derecho y el beneficio común que ofrece a toda una comunidad.

En este mismo sentido, anota Raz que los derechos colectivos existen si cumplen los siguientes requisitos:

Primero, este existe porque un aspecto del interés de los seres humanos justifica tener a alguna persona o personas sujetas a un deber. Segundo, los intereses en cuestión son los intereses de individuos o miembros del grupo $\mathrm{y}$ se entienden como intereses en beneficio público; el derecho colectivo es un derecho a ese bien público porque le sirve a los intereses de los seres humanos como miembros del grupo. Tercero, el interés de ninguno de los miembros individualmente considerado es suficiente en sí mismo para justificar el tener a otra persona sujeta a un deber (1988, p. 208).

Como ejemplo de estos derechos colectivos tenemos el derecho a la autodeterminación que ejemplifica las tres cualidades. Es valorado por la contribución de la autodeterminación al bienestar de los miembros individuales del grupo. La autodeterminación no es tan solo un bien público, sino uno colectivo, y el interés de las personas en él emana del hecho de que son miembros del grupo. Finalmente, aunque muchos individuos tienen un interés en la auto determinación de su comunidad, este es una base inadecuada para tener a otros atados a la obligación de satisfacer dicho interés. El derecho descansa sobre los intereses acumulados de muchos individuos (Raz, 1988).

Estas definiciones nos hacen concluir que los derechos colectivos están dados para ejercerse grupalmente y para asegurar beneficios que solo pueden disfrutarse en colectivo, por tanto, su beneficio en ningún caso podría dividirse y satisfacer el estándar mínimo vital del individuo, y su estatus social, que conlleva a la satisfacción de necesidades, compromete la integridad del ser humano y su desarrollo socioeconómico, tal es el caso de los derechos de los consumidores que se circunscriben al ámbito de las libertades de base social y económica.

Como se busca con el reconocimiento de los derechos sociales fundamentales siguiendo las tendencias del derecho moderno, que opta por ser individualista (Habermas, 1999). La gran ventaja de los derechos individuales -derechos que aseguran al individuo la autoridad de exigir el derecho- es que eliminan riesgos de operaciones asociados con la dependencia de otros para exigir el derecho en su beneficio, mientras al mismo tiempo evitan los problemas de actuación colectiva y el costo de procedimientos mayoritarios para exigir el derecho (Buchanan, 1994). Es así como Habermas (1999) precisa que el individuo, no el grupo históricamente oprimido, es el titular de derechos que nacen de la dialéctica entre la igualdad material y la igualdad jurídica.

\section{Conclusiones}

Los derechos sociales fundamentales presuponen una situación de desigualdad a superar; es el derecho del excluido, del discriminado, del menos protegido, del que menos puede tomar parte de los beneficios de la vida en comunidad. Según Corso (1981), el derecho social sirve para hacer a un lado la desigualdad y la injusticia de la posición de partida. Es un derecho del individuo y no del grupo al que el 
sujeto jurídico pertenece, pero la pertenencia al grupo -social humano- determina la titularidad del derecho (Benjamin, 1993). Es entonces como el individuo -titular exclusivo de los derechos sociales fundamentales-, que se encuentra en situación de desventaja, pretende ejercerlos, y no un colectivo, siguiendo la necesidad del reconocimiento de su autonomía. Pues el reconocimiento de este tipo de derechos no está dado en la pertenencia a un grupo, sino en la importancia y la afectación gravísima a la esfera interna y de desarrollo social del sujeto.

Para finalizar, se considera que los derechos de los consumidores se enmarcan claramente dentro los derechos sociales fundamentales con una titularidad individual, ya que se parte de un concepto económico de una persona que actúa para satisfacer necesidades propias que involucran las esferas más íntimas: salud, alimentación, servicios públicos y vivienda. Los derechos de los consumidores, así como los derechos reconocidos con el carácter de económicos, tienden, por un lado, a proteger a los consumidores individualmente considerados de los perjuicios que las relaciones de consumo mismas podrían acarrearles y, por otro, a preservar el mercado, en cuanto mecanismo de coordinación del proceso económico, sin obviar el interés social.

Así las cosas, no se puede negar que este tipo de derechos implica unas obligaciones positivas, un quehacer por parte del Estado que el individuo puede exigirle, ya que es el más vulnerable dentro de la relación de consumo, pues la balanza de equilibrio que debería existir en dichos vínculos se inclina desfavoreciendo al consumidor.

Por tanto, aunque todos los seres humanos seamos consumidores, no es una colectividad la que disfruta el beneficio de ese bien o servicio. Aunque concurrentemente requiramos a los mismos, pues desde la definición misma de consumidor, que es la persona destinataria de un bien o servicio para su disfrute privado, nos dice que el ejercicio de esta relación no se hace de manera grupal y, por ende, de forma errónea puede tomarse como un derecho colectivo, más aún, si en un nexo real entre derecho y mercado se parte de la premisa de que las personas son diferentes en necesidades, aptitudes, capacidades y recursos (Arango, 2005), y como señala Amartya Sen (2000) en su obra Desarrollo y libertad, la titularidad del derecho por sí sola no tiene valor, lo adquiere verdaderamente cuando puede ejercerse y para el caso de los derechos en cuestión, la categorización actual establecida en nuestra Constitución colombiana es una talanquera a la praxis de estos derechos y difiere de la naturaleza misma de estos, que al encontrar la reconstrucción de su contenido material en el vínculo derecho y mercado, se adscriben dentro de los derechos sociales fundamentales, que son los que protegen a los miembros del cuerpo social en todo lo que atañe a la posesión, producción, administración y distribución de los bienes (Todoli, 2000).

\section{Referencias}

Abramovich, V., \& Courtis, C. (2002). Los Derechos Sociales como Derechos Exigibles. Madrid: Trotta.

Alexy, R. (1995). Recht, Vernunft, Diskurs (2da ed.) (Trad. Jorge Seña). Barcelona: Gedisa.

Alexy, R. (1997). Theorie Der Juristischen Argumentation ( $3 \mathrm{a}$ ed.). Madrid: Centro de Estudios Constitucionales.

Alexy, R. (2003). Los Derechos Fundamentales en el Estado Constitucional Democrático (Trad. A. García). Madrid: Trotta.

Alpa, G. (2004). Derecho del consumidor. Lima: Gaceta Jurídica.

Arango, R. (2005). El Concepto de Derechos Sociales Fundamentales. Bogotá: Legis.

Bassols Coma, M. (1985). Constitución y Sistema Económico. Madrid: Tecnos. 
Baudrillard, J. (1970). La Sociedad de Consumo. Madrid: Siglo XXI.

Benjamin, A. (1993). El Derecho del Consumidor. Buenos Aires: Editorial Astrea.

Bidart, G. (1995). Tratado elemental de derecho constitucional argentino. Buenos Aires: Ediar.

Bidart, G. (2000). Manual de la constitución reformada (3a ed.). Buenos Aires: Ediar.

Borja, R. (1997). Enciclopedia de la Política. México: Fondo de Cultura Económica.

Buchanan, A. (1994). Liberalism and Group Rights. Cambridge: Cambridge University.

Castro De, B. (1993). Los Derechos Económicos, Sociales y Culturales. León: Universidad De León.

Consejo de la Comunidad Europea. (1975). Resolución del 14 de abril de 1975.

Consejo de la Comunidad Europea. (1981). Resolución del 19 de mayo de 1981.

Constitución Política (1991). Congreso de la República de Colombia. Colombia.

Corso, G. (1981). Los Derechos Sociales en la Constitución Italiana. Madrid: Universidad Carlos III de Madrid.

Cuadrado Roura, J. (1995). Introducción a la política económica. México: Mac GrawHill.

Cuevas, H. (2002). Teorías Jurídicas y Económicas del Estado. Bogotá: Universidad Externado de Colombia.

Dworkin, R. (1984). Los derechos en serio. Barcelona: Ariel.
Dworkin, R. (1988). El imperio de la justicia. Barcelona: Gedisa.

Dworkin, R. (1996). Freedom Law, the Moral Reading of the American Constitution. Cambridge: Harvard University.

Edling, A. (1994). Solución de Conflictos, Acceso a la justicia (Trad. Instituto Nacional del Consumo). España: Editorial la Rocca.

Esguerra, J. (2007). La Protección Constitucional del Ciudadano. Bogotá: Legis.

Farina, J. (1997). Contratos comerciales modernos. Buenos Aires: Astrea.

Farina, J. (2004). Defensa del consumidor y del usuario. Buenos Aires: Astrea.

Friauf, K. (1996). Zur Rolle. Der Grundrechte im Sozialstaat (Trad.Centro de Estudios Constitucionales). Madrid: Centro de Estudios Constitucionales.

García, N. (1995). Consumidores y Ciudadanos: Conflictos Multiculturales de la Globalización. México: Editorial Grijalbo.

Gelli, M. (2003). Constitución de la nación argentina, comentada y concordada (2a ed.). Buenos Aires: La ley editores.

Ghersi, C. (1995). Postmodernidad Jurídica. Buenos Aires: Gowa.

Gide, Ch. (1926). Curso de Economía Politica. Paris: Librería de la Vda de Ch. Bouret.

Gozaíni, O. (2005a). Derecho procesal constitucional: Protección procesal del usuario $y$ consumidor. Buenos Aires: RubinzalCulzoni.

Gozaíni, O. (2005b). Protección procesal del usuario y consumidor. Buenos Aires: Rubinzal-Culzoni. 
Habermas, J. (1999). Die Einbeziehung des Anderen. Studien Zur Politischen Theorie (Trad. J. Velasco Arroyo). Barcelona: Paidós.

Hammer, M., \& Champy, J. (1994). Reingeniería. Colombia: Norma.

Ibañez, J. (2001). Estudios de Derecho Constitucional Económico. Bogotá: Pontificia Universidad Javeriana.

Isensee, J. (1980). Verfassung Ohne Soziale Grundrechten. Der Staat. Num.19 (Trad. E. Calderón). Madrid: Taurus.

Kelmelmajer, A. (1991). La protección al consumidor en el derecho privado. Buenos Aires: Juris.

Kelmelmajer, A. (1996). La Protección del consumidor en el derecho comparado (Tomo I). Buenos Aires: Juris.

Lara, R., \& Echaide, J. (2006). Consumo y Derecho "Elementos Jurídico-Privados de Derecho de Consumo”. Madrid: ESIC Editorial.

López Camargo, J. (2003). Derechos del Consumidor: Consagración Constitucional en Latinoamérica. E-Mercatoria, 2(2). Recuperado de: http://www.emercatoria.edu.co/ paginas/volumen2/pdf02/derechos.pdf

López Guzmán, F. (2007). Derecho comercial y societario. Bogotá: Ediciones del Profesional LTDA.

Lorenzetti, R. (1994). Análisis crítico de la autonomía privada contractual. Buenos Aires: Rubinzial.

Lorenzetti, R. (1997). Protección internacional del consumidor. Presentada en II Jornada Uruguaya-Santafesina, Santa Fe.

Lorenzetti, R. (2008). Consumidores. Buenos Aires: Rubinzal-Culzoni.
Madle, J. (1987). La Cultura y los Medios de Comunicación. La Plata: Editorial Asociación Argentina de Filosofía del Derecho.

Marques, C. (1998). Contratos no código de defesa do consumidor: O Novo Regime das relacaos contratuais. Sao Paulo: Revista Dos Tribunais 3. ed. rev., atual e ampl. 2. Tir.

Morales, J. (2002). Derecho Económico Constitucional (4a ed.). Bogotá: ABC.

Noronha, F. (1999). Direito das obrigacoes, responsabilidad civil publica. Sao Paulo: Juris.

Organización de las Naciones Unidas [ONU]. (1985, abril 9). Asamblea general. Resolución No. 39/248. Por la cual se dictan directrices para la protección del consumidor.

Organización de las Naciones Unidas [ONU]. (1997, mayo 13). Informe del secretario general del consejo económico y social.

Organización de las Naciones Unidas [ONU]. (1998, febrero, 19). Informe del secretario general sobre el desarrollo sostenible del consejo económico y social de la ONU.

Organización de las Naciones Unidas [ONU]. (1999, mayo 17). Informe de la comisión de ciencia y tecnología para el desarrollo del consejo económico y social de la ONU. Cuarto período de sesiones. Ginebra.

Pellegrini, A. (1992). El nuevo proceso brasileño del consumidor. Estudio sobre Consumo, 25, 13-24.

Pérez, L. (2004). Derecho Social del Consumo. Buenos Aires: La Ley.

Pisarello, G. (2007). Los derechos sociales y sus garantías: Elementos para una reconstrucción. Madrid: Trotta. 
Raz, J. (1988). La Moral de la Libertad. Madrid: Centro de Estudios Constitucionales.

Rebollo, M. (1990). La actividad administrativa de limitación y la ley general para la defensa de los consumidores y usuarios, en curso sobre el nuevo derecho del consumidor. Madrid: Ministerio de sanidad y consumo; Instituto nacional del consumo.

Rica, G. (1998). Facticidad y Validez (Trad. M. Jiménez Redondo). Madrid: Trotta.

Rincón, J. (2004). Las generaciones de los derechos fundamentales y la acción de la administración pública. Bogotá: Universidad Externado de Colombia.

Rinessi, A. (2006). Relación de consumo y derechos del consumidor. Buenos Aires: Astrea.

Rivero, J. (1997). ¿Quo Vadis Derecho Del Consumidor?. San José Costa Rica: Librería Barrabás.

Sen, A. (2000). Libertad y desarrollo. Barcelona: Planeta.

Sentencia T-406 (1992, junio 5), Acción de tutela. M.P. Ciro Angarita Baron. Corte Constitucional.
Sentencia T-160 (2011, marzo 10), Acción de tutela. M.P. Humberto Sierra Porto. Corte Constitucional.

Stiglitz, R. (1993). Defensa de los consumidores de productos y servicios. Buenos Aires: Astrea.

Todoli, J. (2000). Moral. Economía y humanismo: Los derechos económico-sociales en las declaraciones de los derechos y textos de las mismas. Madrid: Instituto social de león XIII.

Weber, M. (1995). Ética protestante y el espiritu del capitalismo: Critica De la modernidad. México: Fondo de Cultura Económica.

Weingarten, C. (2007). Derecho del consumidor. Buenos Aires: Editorial Universidad.

Wildhaber, L. (1972). Soziale Grundrechte. In Saladin Der Staat als Aufgabe. Basel: Helbing \& Lichtenhahn.

Zuluaga, M. (1998). Hacia una política y un derecho del consumo en Colombia en política y derecho del consumo. Bogotá: El navegante editores. 
